\title{
DEALING WITH THE INCREASED ASSESSMENT WORKLOAD OF WORK- INTEGRATED LEARNING IN A CAPSTONE UNIT FOR AN UNDERGRADUATE MAJOR IN STATISTICS
}

\author{
Ayse Aysin Bilgin and Peter Petocz \\ Macquarie University, Australia \\ ayse.bilgin@mq.edu.au
}

Bringing real problems into curriculum is not an easy job but assessing such student work is even harder, especially when universities are run like businesses where academics are given only limited hours to assess student work. The literature documents that authentic problems are more engaging for students and thus there is no argument against having such problems in the curriculum. However, the literature also shows that assessment of such student work is costly in terms of time.

We have developed marking rubrics to standardise marking such assessment tasks, as well as providing some guidance to students on what is expected of them. A mentoring model, putting ourselves (as lecturers) as part of the students' work, but letting students make decisions and solve problems, has been at the heart of our rubric development. We will share our experience of dealing with the increased assessment workload arising from incorporating work-integrated learning into a capstone unit for an undergraduate major in statistics by providing examples of how real projects that are beneficial to students and industry can be assessed in a way that is time efficient for academics. The example rubrics can be adopted, further developed or modified by colleagues who are hesitant to move into this direction.

Our experience shows that assessments of real projects can be completed more efficiently by utilising such marking rubrics. Students seem satisfied with the mentoring and guidance they receive, and with the feedback they get for their projects. Given that such marking rubrics have not been widely developed or used in statistics education generally, nor specifically for real projects, we believe that our examples will be helpful for statistics educators generally. 